\title{
USING ABSORBANCE AS A MEASURE OF TURBIDITY IN HIGHLY CAUSTIC SOLUTIONS \\ Tomoko Radomirovic ${ }^{1}$, Peter Smith ${ }^{2}$, Franca Jones ${ }^{1 *}$ AJ Parker CRC for Integrated Hydrometallurgy Solutions \\ ${ }^{1}$ Department of Chemistry, Curtin University GPO Box U1987 Perth WA 6845, Tel: 6189266 7677, Fax: 6189266 4699, email: F.Jones@curtin.edu.au \\ ${ }^{2}$ CSIRO Minerals Down Under Flagship, Waterford WA
}

\begin{abstract}
This note shows that the dissolution kaolin and its subsequent re-crystallization as DSP can be monitored using a simple UV-vis method that measures the turbidity of the system. The method is shown to be accurate, reproducible and sensitive. The dissolution of kaolin can be accurately determined by way of a solids calibration curve and this is supported by simultaneous measurements of the dissolved silicate by an inductively coupled plasma (ICP) technique. Additionally, turbidity is often used to measure induction times of nucleation thus the method can monitor dissolution and nucleation simultaneously. It must be remembered, however, that turbidity will show different behaviour to ICP when phenomena such as settling and aggregation occur thus these processes must be considered when interpreting data. Finally, the size limit of the turbidimetric technique must be determined as this, too, can influence the interpretation of data.

\section{Notation and units}

The following conventions are used in this paper:

$\mathrm{C}=$ total caustic expressed as equivalent sodium carbonate $\left(\mathrm{g} / \mathrm{L} \mathrm{Na} \mathrm{CO}_{3}\right)$

$\mathrm{A}=\mathrm{Al}$ content expressed as equivalent alumina $\left(\mathrm{g} / \mathrm{L} \mathrm{Al} \mathrm{O}_{3}\right)$

$\mathrm{S}=$ caustic + carbonate content expressed as equivalent sodium carbonate $\left(\mathrm{g} / \mathrm{L} \mathrm{Na} \mathrm{CO}_{3}\right)$

$\mathrm{A} / \mathrm{C}=$ ratio of $\mathrm{A}$ and $\mathrm{C}$ (gives an indication of the saturation state of the liquor)
\end{abstract}

\subsection{Introduction}

The Bayer process has long been used to refine bauxite to alumina and involves the dissolution of the aluminium containing minerals in highly caustic solutions at elevated temperatures $\left(\geq 150^{\circ} \mathrm{C}\right)$. During this process reactive silicates (mainly clays) can dissolve leading to unwanted consequences such as scale formation, loss of caustic (Whittington et al., 1998; Duncan et al., 1995; Jamialahmadi and Muller-Steinhagen, 1993). To ensure that the silicate levels in the Bayer liquor are low a unit process is normally introduced prior to the bauxite digestion stage called ore pre-desilication. In this unit process, the reactive silicates are allowed to dissolve and re-precipitate as desilication products (DSPs). DSPs are aluminosilicates that have pseudo-zeolitic structures based on sodalite or cancrinite depending on formation temperature and other conditions (Hassan and Grundy, 1984; Hassan and Grundy, 1989; Lowe et al., 2006; Xu et al., 2010).

The crystallization of DSPs is not yet fully understood. While the process is known to involve dissolution of kaolin (and other reactive silicas) and an increase in the $\left[\mathrm{SiO}_{2}\right]$ liquor concentration until DSP formation begins, whether this is primary or secondary nucleation followed by a growth process is not clear, although there has been the suggestion that kaolin templates the formation of DSP (Lowe et al., 2005). To this end we have developed a UV-Vis method to measure the turbidity of a solution over time. The absorbance at a wavelength of $900 \mathrm{~nm}$ is chosen since at this wavelength absorbance of the light by either the solid or solution should be minimal and this has previously been shown to correlate to turbidity (Yang and Hogg, 1979).

Optical density or turbidity is impacted by many parameters such as particle number, particle size and particle shape (Kleizen et al., 1995). However, the main impact is that of particle number and size (Kleizen et al., 1995). As such, if particles are dissolving then this should be evident by a change in the turbidity of the solution (particles becoming smaller and number reducing). In addition, when light is passed through a slurry both absorption of the light by the particles and scattering of the light by the particles occurs. Thus, in order to obtain a true measure of optical density, absorption must be reduced or eliminated. For this reason many light scattering techniques employ long wavelengths (infrared or $>900 \mathrm{~nm}$ ) however, this is offset by the fact that smaller particle sizes are best detected by shorter wavelengths Blume and Greenberg, 1975). In this study a wavelength of $900 \mathrm{~nm}$ is used. In addition, turbidimetric techniques have been used to investigate nucleation events by measuring the 
so called 'induction time (Mullin, 1961). In principle, this technique should be able to give information on both dissolution and nucleation events.

In this note, we show how the turbidity results can be used to determine the dissolution of kaolin in caustic and Bayer liquors and investigate whether precipitation of DSPs in the presence of kaolin solids can be detected.

\subsection{Experimental}

2.1 Materials and synthetic liquor preparation

Sodium hydroxide (AR grade, Aldrich), sodium carbonate and sodium sulfate (AR grade, Aldrich) were used to make the synthetic liquor by initially dissolving the sodium hydroxide into water. Subsequently, gibbsite (C33, Alcoa of Arkansas, Pty. Ltd.) was added and heated to dissolve all the solids. Sodium carbonate $(30 \mathrm{~g} / \mathrm{L})$ and sodium sulfate $(10 \mathrm{~g} / \mathrm{L})$ were dissolved in water separately and once the gibbsite was dissolved the two solutions are mixed, filtered and allowed to cool prior to adjusting to the desired volume.

The kaolin was a Snobrite 65 kaolin from Unimin Corp. (Australia). It was characterised by SEM, DLS, and XRD. The chemical composition of this kaolin as given by XRF is reported in Temuujin et al. (2001) and is given in Error! Reference source not found..

\section{Table 1. XRF composition of kaolin used}

\begin{tabular}{|ll|}
\hline & wt\% \\
\hline $\mathrm{SiO}_{2}$ & 46.36, \\
$\mathrm{Al}_{2} \mathrm{O}_{3}$ & 37.6, \\
$\mathrm{Fe}_{2} \mathrm{O}_{3}$ & 0.94 \\
$\mathrm{TiO}_{2}$ & 0.8 \\
$\mathrm{MgO}$ & 0.24 \\
$\mathrm{~K} \mathrm{O}$ & 0.22, \\
$\mathrm{CaO}$ & 0.2, \\
$\mathrm{Na}_{2} \mathrm{O}$ & 0.13 \\
$\mathrm{SO}_{3}$ & 0.07 \\
$\mathrm{LOI}$ & 13.5 \\
\hline
\end{tabular}

\subsection{UV-vis method}

The UV-vis method developed measures the absorbed light at a fixed wavelength where absorption from the suspending liquid is expected to be negligible. In this way the UV instrument can be used as a turbidity meter as discussed above. Although a flow through option was available, it was found that the particles aggregated and this blocked consistent flow through the cell. By placing the equipment near the UV instrument and limiting the exposure to ambient conditions, temperature effects were minimised making a sampling procedure possible. A GBC UV-Vis 916 instrument was used throughout this work.

In the presence of solids, the turbidity can also be used as a measure of the solids content provided a suitable fit to known solids is obtained. Such a fit is shown in Fig. 1 for kaolin (no difference was observed between the absorbance measured in caustic to Bayer liquor). 


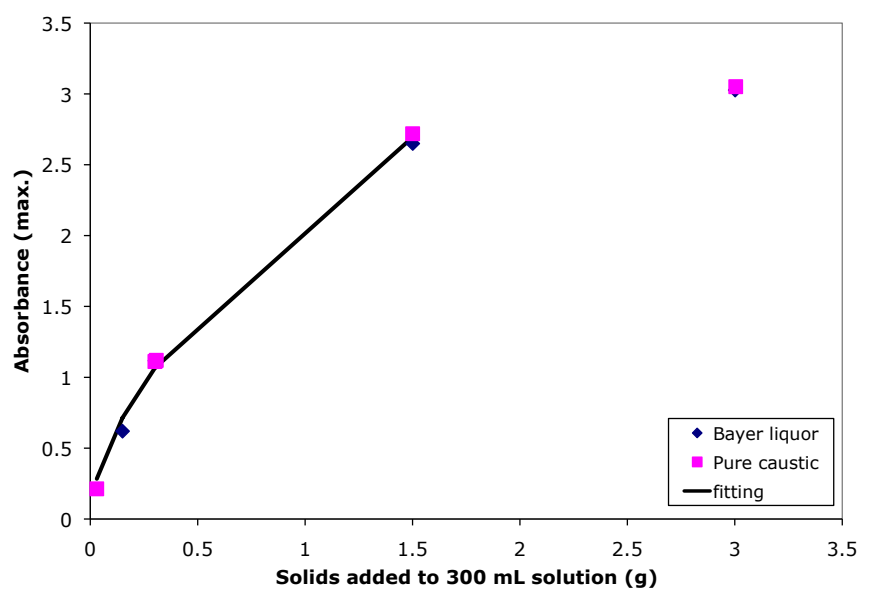

Figure 1. UV-Vis Absorbance (at $900 \mathrm{~nm}$ ) versus solids added relationship for kaolin solids

The values at $3 \mathrm{~g}$ kaolin addition were not used for the fitting since these were deemed to be at the absorbance limit of the instrument. Using this relationship, the absorbance could be converted to the kaolin solids present (and subsequently to the amount of kaolin dissolved).

Absorbance $=\left(2.01^{*}[\text { Kaolin Solids }]^{0.610}+0.1078\right)$

The sum of the residuals squared was 0.039 . The values obtained from fitting were less than $5 \%$ from the known value except for those absorbance values less than 0.3. In this situation a fixed error of \pm 0.05 absorbance units was more appropriate.

\subsection{Liquor Analysis}

The spent liquor was analysed using the method of Connop (1996) and the following characteristics were determined. The composition of the liquor was not varied.

$C=250 \pm 20$

$A=75 \pm 13$

$S=280 \pm 20$

$\mathrm{A} / \mathrm{C}=\mathbf{0 . 3} \pm \mathbf{0 . 0 5}$

$\mathrm{An} A / C$ value of 0.3 is indicative of a spent liquor in a Bayer refinery.

In addition, as mentioned above, $10 \mathrm{~g} / \mathrm{L}$ sodium sulfate was also present in the liquor. Pure caustic solution had a $\mathrm{C}=280$ with no carbonate, gibbsite or sulfate present.

\section{$2.4 I C P$}

A sample was taken from the reactor containing a known amount of kaolin and caustic (or Bayer liquor) and filtered through a caustic resistant $0.2 \mu \mathrm{m}$ membrane. An aliquot from the filtrate, $2 \mathrm{~mL}$, was then added to $18 \mathrm{~mL}$ pure caustic and acidified prior to analysing against relevant standards by ICP. For dissolution studies, the initial kaolin solids content was known and the reaction sampled at known time intervals.

\subsection{Kaolin characterisation}

As seen in Fig. 2a, the original kaolin particles are flat platelet-like particles agglomerated into larger structures of $\geq 2 \mu \mathrm{m}$ in size. The individual particles are more in the range of $100-500 \mathrm{~nm}$ in radius and this is confirmed by DLS particle sizing (Malvern NanoZeta ZS) as shown in Fig. 2c. XRD confirmed kaolin as the only crystalline phase present (Fig. 2b). 

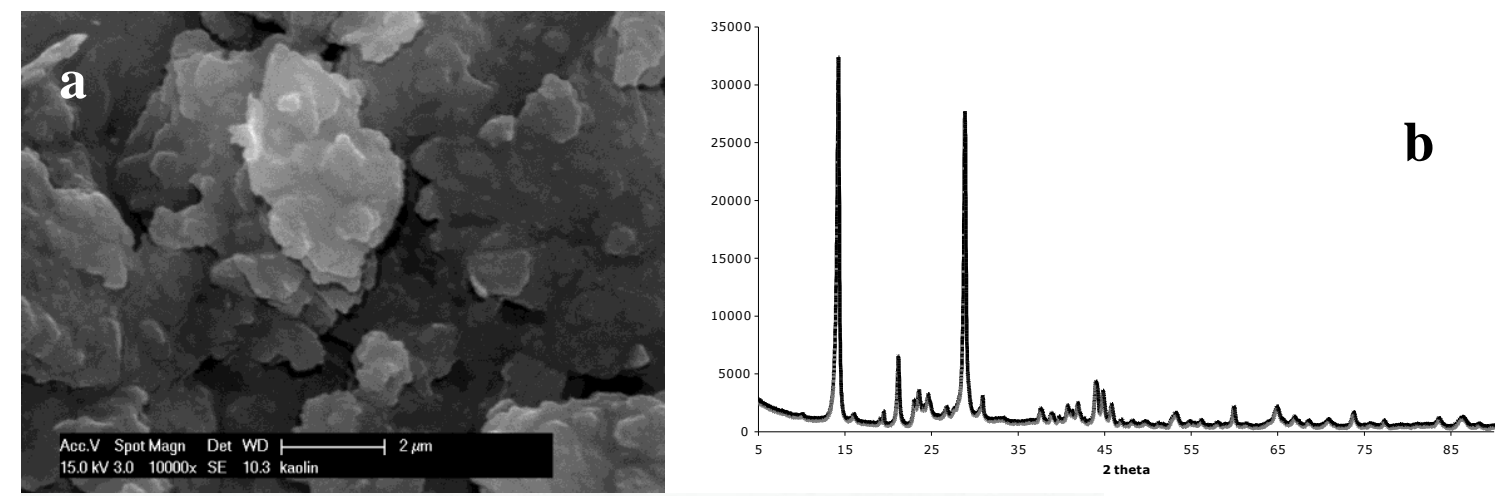

Size Distribution by Irtensity

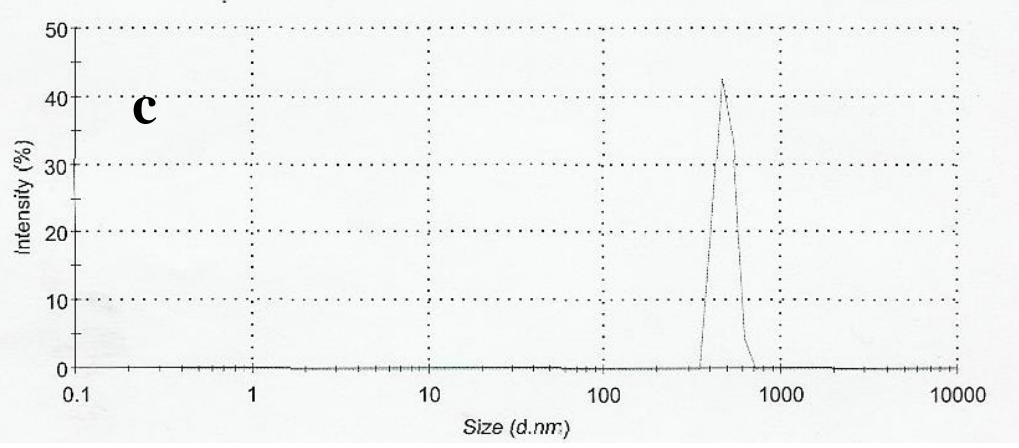

Figure 2. Kaolin characterisation: (a) SEM image, (b) XRD, and (c) DLS of sample

\subsection{Monitoring of kaolin reactions}

Caustic or Bayer liquor $(300 \mathrm{~mL})$ was added to a stainless steel jacketed reactor and equilibrated to temperature using a water bath (Grant). A stainless steel stirring rod fitted to an overhead stirrer was used to mix the slurry at $400 \mathrm{rpm}$. A sample of the liquor without solids was always measured prior to addition of the solids and this represented $\mathrm{t}=0$. A known quantity of kaolin (pre-dispersed in a small amount of solution by ultrasonication) was then added to the reactor at $t=5 \mathrm{~min}$ and the reaction sampled at known time intervals. The sample was either filtered for ICP analysis or was placed into a quartz cuvette for UV-vis analysis. The samples taken for UV-vis analysis were inverted prior to placing into the instrument to re-disperse the solids and the maximum absorbance reading was taken (since settling of particles can occur over time).

\subsection{Results and Discussion}

A run was performed in which the absorbance was taken and the samples subsequently prepared for Si determination using ICP. The results below (Fig. 3) show that the UV method is behaving like a turbidity meter and often (but not always) mirrors the ICP results. This is because ICP measures the silicate in solution (strictly speaking any silicate that passes through the $0.2 \mu \mathrm{m}$ membrane) whereas the UV-Vis instrument measures the scattered light from the suspended particles. As the kaolin dissolves in caustic, the absorbance decreases over time (less turbid solution). This decrease was then converted to the dissolved $\left[\mathrm{SiO}_{2}\right]$ using the calibration curve of absorbance to solids, assuming the theoretical structure of kaolin is $\mathrm{Al}_{2} \mathrm{Si}_{2} \mathrm{O}_{5}(\mathrm{OH})_{4}(\mathrm{MW}=258.172)$ and the fact that the dissolved solids $=$ initial solids - solids remaining. Using these assumptions the data could be compared to the ICP data measuring the dissolved silicate directly. 


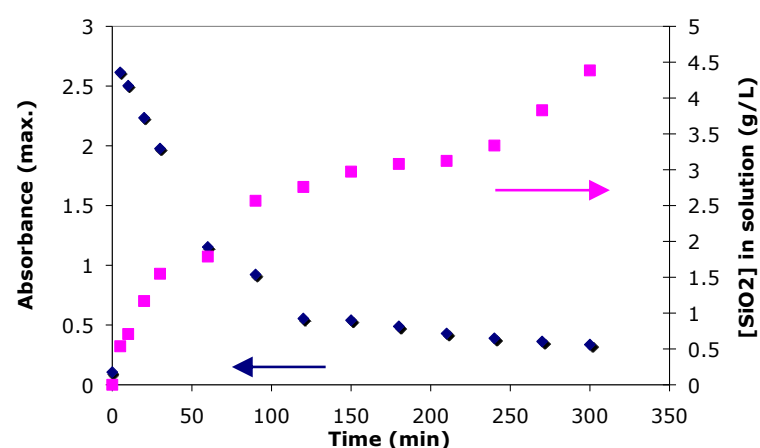

(a)

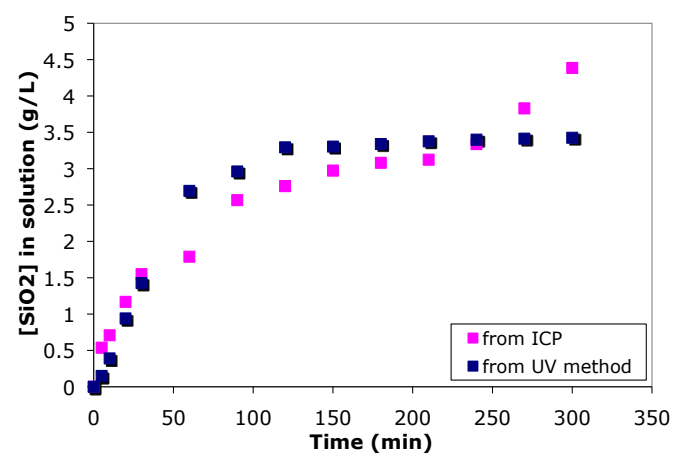

(b)

Figure $3 . \quad$ a) $\mathrm{SiO}_{2} \mathrm{~g} / \mathrm{L}$ in solution (pink squares) determined from ICP compared to maximum Absorbance at $900 \mathrm{~nm}$ (blue squares) and (b) calculated $\mathrm{SiO}_{2}$ levels $(\mathrm{g} / \mathrm{L}$ ) in solution using the absorbance versus kaolin solids curve and the actual $\mathrm{SiO}_{2} \mathrm{~g} / \mathrm{L}$ in solution as determined from ICP.

In the early stages of dissolution the ICP and UV-vis method are in excellent agreement. However, at the longer time periods the agreement lessens. The ICP suggests further dissolution is occurring but the UV-vis method does not. Given that the UV-vis method is measuring the turbidity and is related to both particle size and number, it will not always coincide with a method measuring concentration. The results above may be caused by two possible events; firstly, the sizes of the particles dissolving may be below the detection limit of the UV-vis method or it could be due to small kaolin particles reporting to the filtrate and being measured by ICP. Nevertheless, the UV method does appear to be giving an accurate measure of the turbidity and concentration in the early stages of dissolution.

\subsection{Reproducibility and repeatability}

Reproducibility runs were performed where no change in absorbance was observed (low values where sodium metasilicate solution had been added at a level where no impact on absorbance was observed, this can be seen in Fig. 4a) and at higher values where the absorbance changed with time (1.5 g kaolin added to caustic, shown in Fig. 4b).

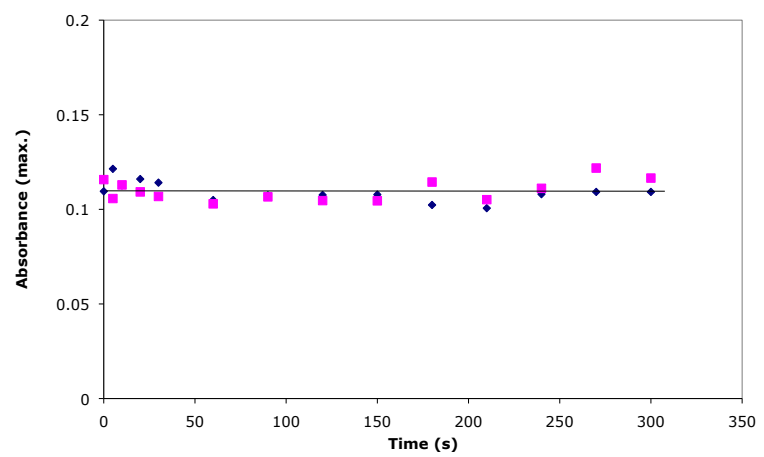

a

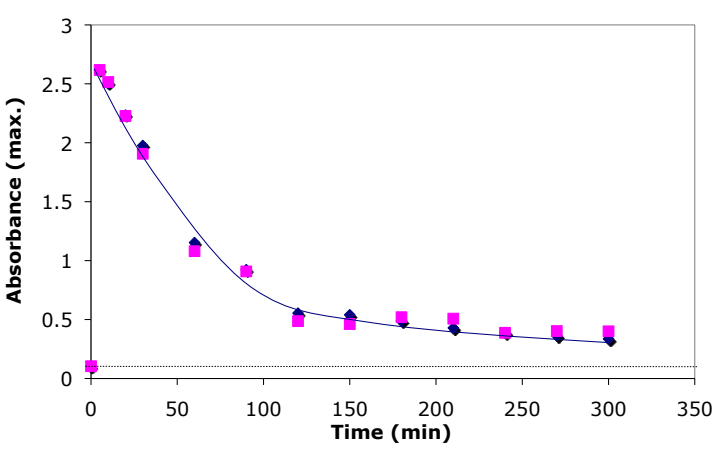

b

Figure 4. Reproducibility curves A) low Absorbance values (0g kaolin in Bayer liquor) B) higher and changing absorbance values (1.5g kaolin in $300 \mathrm{~mL}$ Bayer liquor)

In addition, it was determined that the method was only able to detect particles $\geq 400 \mathrm{~nm}$ in diameter since particles of this size were observed in SEM images but did not correspond to any absorbance changes. It is well known that light scattering methods have size detection limits and that the size detectable will depend on the wavelength used (Biume and Greenberg, 1975).

\subsection{Using the method to monitor kaolin dissolution and DSP formation}

In pure caustic the kaolin dissolves as expected. At low solids content the dissolution is almost complete after 360 minutes. At higher kaolin contents, the dissolution noticeably slows suggesting that 
the solubility limit of silicate is being reached (Fi. 5b). Although most of the solids have dissolved at $0.05 \mathrm{wt} \%$, the plate-like particles of kaolin are still visible in the SEM image (see Fig. 5a). The surface is, however, much smoother and etched areas are observable (c/f Fig. 2a). Clear etch pits of defined shape are not observed, suggesting kaolin does not dissolve in this way in caustic solution.

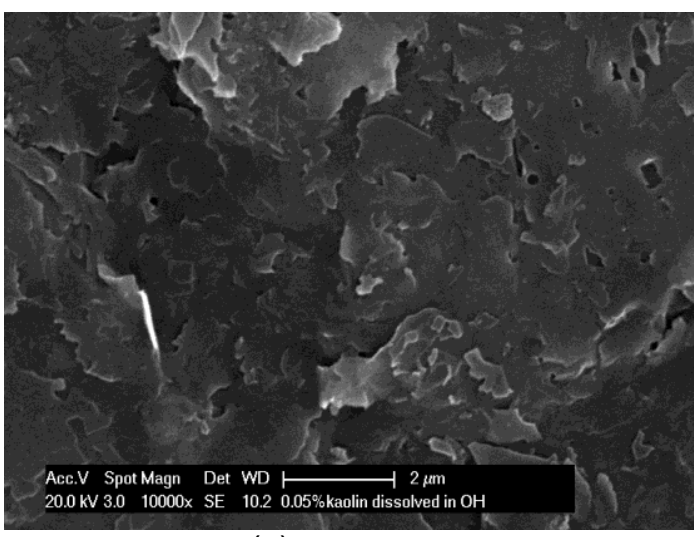

(a)

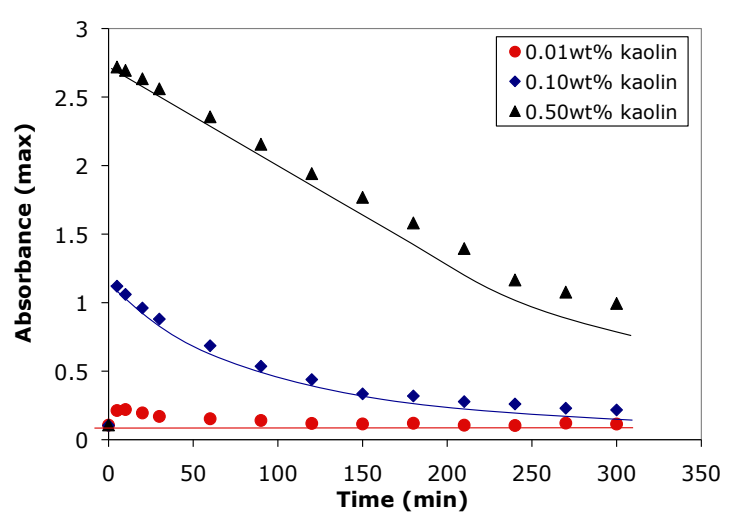

(b)

Figure $5 . \quad$ (a) SEM image of dissolved kaolin after exposure to caustic (b) Absorbance versus time of different kaolin loadings in pure caustic at $80^{\circ} \mathrm{C}$

In synthetic Bayer liquor the dissolution of kaolin is slower (Fig. 6). A simple equilibrium argument of kaolin dissolving into its constituent parts

$6 \mathrm{OH}^{-}+\mathrm{Al}_{2} \mathrm{Si}_{2} \mathrm{O}_{5}(\mathrm{OH})_{4} \rightarrow 2 \mathrm{Al}(\mathrm{OH})_{4}^{-}+2 \mathrm{SiO}_{3}{ }^{2-}+\mathrm{H}_{2} \mathrm{O}$

shows that the presence of aluminate in solution would be expected to lower the extent of kaolin dissolution into the liquor and this may also impact on the kinetics.

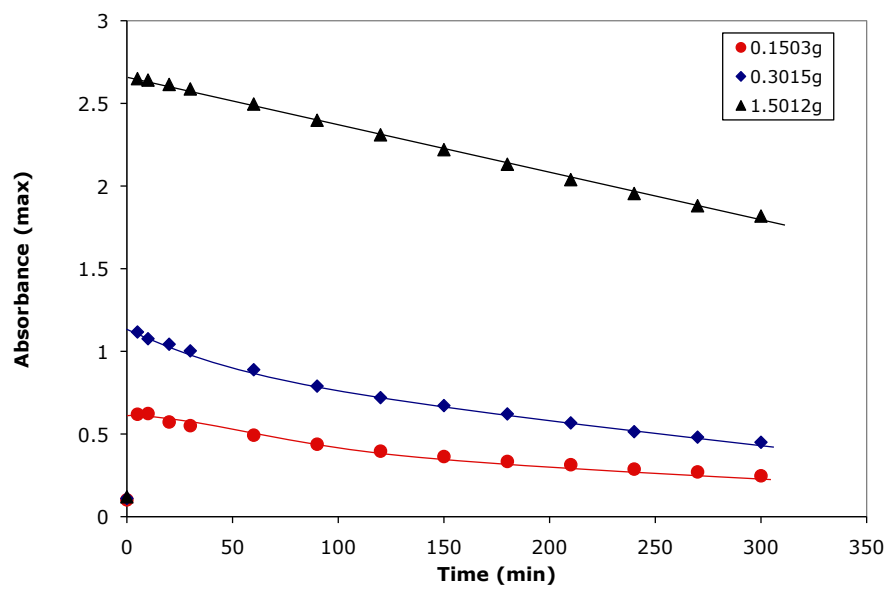

Figure 6. Dissolution behaviour of kaolin (at different loadings) in synthetic Bayer liquor at $80^{\circ} \mathrm{C}$ (lines drawn to aid reader only)

The solids content of kaolin was then raised further and a noticeable reversal in the absorbance is observed (Fig. 6a). Due to the absorbance being close to the limit of the instrument, the slurry was diluted (x2), however, the data showed the same trend. As can be seen from the SEM image, new particles typical of DSP and having the 'woolly ball' morphology were visible, confirming the reversal in the absorbance is due to crystallization of the new particles. XRD confirmed that the solids formed were nosean particles (data not shown). The nosean structure is based on sodalite where sulfate has been trapped within the sodalite cage (Hassan and Grundy, 1984; Hassan and Grundy, 1989; Lowe et al., 2006; Xu et al., 2010). 


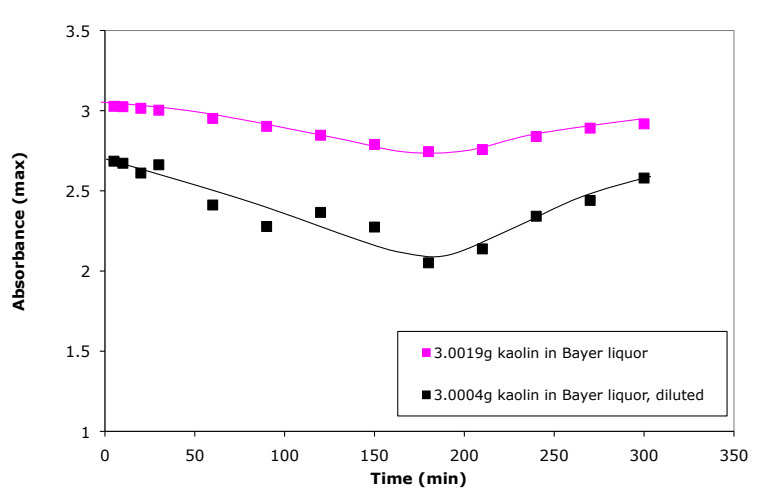

(a)

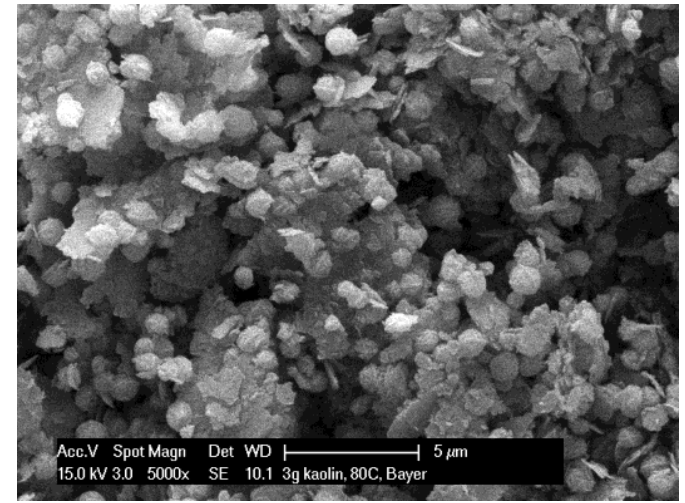

(b)

Figure 7. (a) Absorbance versus time when kaolin is treated with synthetic Bayer liquor at $80^{\circ} \mathrm{C}$ and $1 w t \%$ solids loading (b) SEM image of resultant particles

At $90^{\circ} \mathrm{C}$ the same behaviour is observed. Once again, this data was compared to results obtained by ICP analysis on the filtrate obtained from sampling (see Fig. 8a). The calculated solids dissolution curve is shown (Fig. 8b) although it must be stressed that this curve makes the assumption that the solids are kaolin solids. Thus, only the dissolution part of the curve is strictly comparable to the ICP data. The results clearly show that the UV-vis method is comparable to the ICP results when used appropriately. It is interesting to note that the maximum in solution silicate concentration from ICP is obtained just before the minimum in turbidity and this could be because there is an induction time between the achievement of supersaturation and the onset of nucleation (in this case surface nucleation as shown in Fig. 7b), however, it might also be due to the lower sensitivity of the turbidity method or a combination of both.

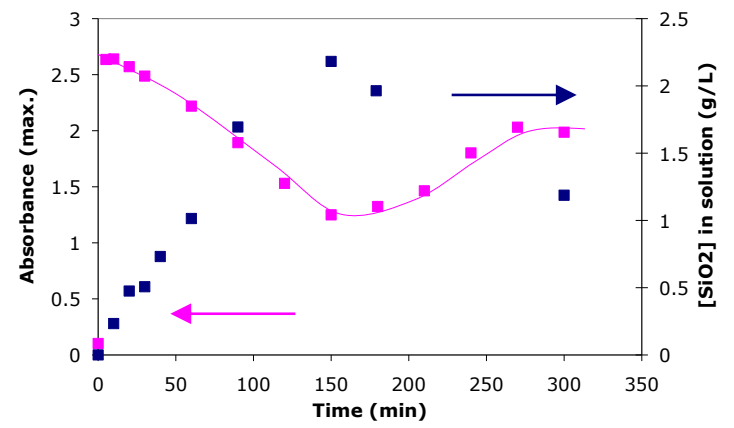

(a)

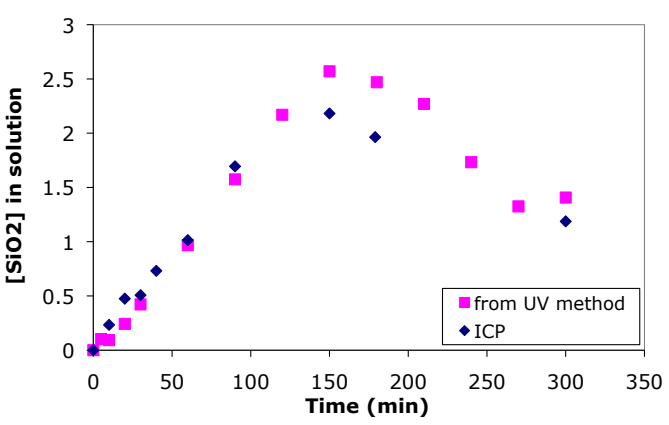

(b)

Figure $8 . \quad$ (a) kaolin solids ( $1.5 \mathrm{wt} \%$ ) at $90^{\circ} \mathrm{C}$ in synthetic Bayer liquor, as followed by the UV-vis method (pink squares) and by ICP (blue squares) and (b) $\mathrm{SiO}_{2}(\mathrm{~g} / \mathrm{L})$ in solution as determined from the absorbance versus solids curve (pink squares) compared to the ICP measured values (blue squares)

\subsection{Summary and Conclusions}

We have shown that a turbidimetric technique can follow kaolin dissolution in caustic and synthetic Bayer liquors at temperatures up to $90^{\circ} \mathrm{C}$. The method allowed calibration of the solids content, which could be used to determine the solids dissolved and to monitor dissolution with time. Comparison to ICP data shows that the accuracy and precision of the turbidimetric technique was excellent while the two methods were measuring the same phenomenon. There are situations, however, where changes in the turbidity will not reflect concentration effects (such as agglomeration, sedimentation etc.).

The method was also used to monitor kaolin dissolution in synthetic Bayer liquors at levels where DSP formation was expected. This showed that initially the turbidity decreases during the dissolution (of kaolin) phase and then increases during the nucleation and growth (of DSP) phase. Thus, this simple turbidimetric technique can be used to monitor such events. It is clearly shown that the DSP particles 
initially grow on the surface of the kaolin suggesting a heterogeneous nucleation event, however, what is not clear is whether these newly formed DSP particles then go on to nucleate further DSP growth via a secondary nucleation mechanism. This is the focus for this work into the future.

Perhaps more interesting is that this method can be applied more generally to different systems in highly caustic or acidic environments. The success of the method depends on well-characterised solids and reproducible solids sampling.

\section{Acknowledgements}

F. Jones, T Radomirovic and P. Smith gratefully acknowledge that this research has been supported under the Australian Government's Cooperative Research Centre (CRC) Program, through the AJ Parker CRC for Integrated Hydrometallurgy Solutions.

\section{References}

Blume, P. ; Greenberg, L. J. (1975), "Application of differential light scattering to the latex agglutination assay for rheumatoid factor", Clinical Chemistry, 21(9), 1234-1237.

Connop, W. L. (1996), "A new procedure for the determination of alumina, caustic and carbonate in Bayer liquors" Proceedings of the $3^{\text {rd }}$ Alumina Quality Workshop, Darwin Australia, 321-330.

Duncan, A.; Müller-Steinhagen, H.; Verity, B.; Welch, B. (1995), "An Investigation of Desilication Kinetics in Spent Bayer Liquor", Light Metals, 37-44.

Hassan, I.; Grundy, H. D. (1984), "The crystal structures of sodalite-group minerals", Acta. Crystallogr. B40, p. 6-13.

Hassan, I.; Grundy, H. D. (1989), "The structure of nosean, ideally $\mathrm{Na}_{8}\left[\mathrm{Al}_{6} \mathrm{Si}_{6} \mathrm{O}_{24}\right] \mathrm{SO}_{4} \cdot \mathrm{H}_{2} \mathrm{O}$ ", Can. Mineral. 27, p. 165-172.

Jamialahmadi, M.; Muller-Steinhagen, H.; Robson, B. (1993), "Effect Of Process Parameters On Scale Formation From Spent Bayer Process Liquor -Experimental Observations Part l", Journal of Aluminium 69 920-923.

Kleizen, H. H.; de Putter, A. B.; van der Beek, M.; Huynink, S. J. (1995)," Particle concentration, size and turbidity", Filtration \& Separation, 32(9), 897-901.

Lowe, J. L.; Hart, R. D.; Smith, P. G.; Rohl, A. L.; Parkinson, G. M. (2005), “Understanding growth of DSP in the presence of inorganic ions", Proceedings of the $7^{\text {th }}$ Alumina Quality Workshop, Perth, Australia, 168-173.

Lowe, J. L.; Rohl, A. L.; Gale, J. D.; Smith, P. G.; Parkinson, G. M. (2006), "Incorporation of impurity anions into DSP: insights into structure and stability from computer modelling", Molecular Simulation, 32(1), $35-44$.

Mullin, J. W. (1961), Nucleation. In Crystallization, 3rd ed.; Butterworth-Heinemann: Oxford, pp $172-$ 201.

Temuujin, J.; Rickard, W.; Lee, M.; van Riessen, A. (2011), "Preparation and thermal properties of fire resistant metakaolin-based geopolymer-type coatings", Journal of Non-Crystalline Solids, 357(5) 1399-1404.

Whittington, B. I.; Fletcher, B. L.; Talbot, C. (1998), "The effect of reaction conditions on the composition of desilication product (DSP) formed under simulated Bayer conditions", Hydrometallurgy 49 1-22. 
Xu, B.; Smith, P.; Wingate, C.; De Silva, L. (2010), "The effect of calcium and temperature on the transformation of sodalite to cancrinite in Bayer digestion", Hydrometallurgy, 105(1-2), 75-81.

Yang, K. C.; Hogg, R. (1979), "Estimation of Particle Size Distributions from Turbidimetric Measurements", Analytical Chemistry, 51(6), 758-763. 